\title{
Dampak Sosial Budaya Pengembangan Dusun Sade Sebagai Dusun Wisata Di Kabupaten Lombok Tengah
}

Nur Kumala Sari a, 1, Saptono Nugroho a, 2

1nurkumalaworld@gmail.com,2saptono_nugroho@unud.ac.id

a Program Studi S1 Destinasi Pariwisata, Fakultas Pariwisata,Universitas Udayana, Jl. Dr. R. Goris, Denpasar, Bali 80232 Indonesia

\begin{abstract}
Sade is one of tourism villages located in Sub-district of Pujut, Central Lombok Regency. The development of the tourism village in Sade has given many impacts such as socio-cultural impact. The community of Sasak Tribe in Sade depends on globalization. It caused the intensive communication between Sade's community with tourist and people around. The community can not decline the tourism development which offer many economically advantages.

The method of this research using qualitative approach. This research uses both qualitative and quantitative data which collect by observation, interview and documentation. The informant chosen by procedure purposive method. In this report data will display by description and table. The parameter of this research is limited by concept socio-cultural impact, culture and tourism village.

The results of this research shows the socio-cultural condition of Sade's community before becoming as a tourism village is stable. They have being impacted mundane in agriculture sector and local organization. Local language is used in their daily life. However, after being a torism village there is complexity livelihood transformation from agricultural to tourism sector. Some new organizations appear such us Kelompok Sadar Wisata (Pokdarwis) and the local manager of Sade Tourism Village. The other impact is the community use foreign languages to communicate with tourist. However, the changes that have taken place shows that Sade's culture is not weak. Despite the changes but their culture and the local ethnic identity is not affected by tourism activities.
\end{abstract}

Keywords : socio-cultural impact, tourism development, tourism village

\section{PENDAHULUAN}

Pulau Lombok merupakan salah satu destinasi yang terkenal di Indonesia. Perkembangan pariwisata di Lombok tidak terlepas dari pengembangan 10 destinasi baru yang disebut Bali baru. Eksistensi pulau Lombok didukung dengan meningkatnya jumlah wisatawan yang ada. Tercatat dari tahun 2011-2015, jumlah kunjungan wisatawan mengalami peningkatan dari sembilan ratus ribu menjadi dua juta tiga ratus ribu wisatawan.

Salah satu destinasi yang memiliki beragam daya tarik di pulau Lombok yaitu Kabupaten Lombok Tengah. Kabupaten Lombok tengah terdapat daya tarik wisata yang cukup populer yaitu Dusun Sade. Dusun Sade merupakan salah satu dusun wisata yang terletak di Kecamatan Pujut, Kabupaten Lombok Tengah. Dusun tradisional ini menawarkan atraksi budaya Suku Sasak berupa arsitektur rumah khas, kebiasaan masyarakat lokal dan juga hasil karya cipta masyarakat berupa tenun khas Lombok serta proses pembuatannya.
Semenjak berkembangnya pariwisata Lombok pada tahun 1989, melalui program Pemerintah Provinsi Nusa Tenggara Barat (NTB) dengan menerbitkan Peraturan Daerah No.9 tahun 1989 tentang 15 Kawasan Pariwisata di NTB salah satunya Kawasan Pariwisata Desa Wisata Dusun Adat Sade, Desa Rembitan, Kecamatan Pujut, Kabupaten Lombok Tengah. Hal ini menjadikan Dusun Sade semakin terkenal.

Eksistensi masyarakat Dusun Sade juga diperkuat oleh Pemerintah dengan dimasukkannya Dusun Sade kedalam Kawasan Srategis Pariwisata Daerah Nusa Tenggara Barat menurut Peraturan Daerah Provinsi Nusa Tenggara Barat No.7 Tahun 2013. Dalam peraturan ini Dusun Sade termasuk kedalam Kawasan Kuta-Mandalika. Dalam perkembanganya masyarakat Sade tidak terlepas dari pengaruh arus globalisasi. Hal ini dipengaruhi oleh intensnya komunikasi masyarakat Sasak Sade dengan komunitas disekitarnya. Hal ini tidak dapat dipungkiri, Karena pariwisata menawarkan pundi-pundi rupiah yang sangat menguntungkan secara ekonomi bagi masyarakat Dusun Sade. 
Seiring berjalannya waktu dengan status Dusun Sade sebagai dusun wisata, secara sadar ataupun tidak banyak budaya yang akan ditransformasikan oleh masyarakat lokal melalui interaksi sosial dengan wisatawan. Hal ini berpengaruh secara signifikan terhadap perubahan tatanan sosial, dan seringkali berdampak pada perubahan sosial primer seperti ekonomis, teknologis, geografis dan biologis sebagai dampak dinamika modernisasi di masyarakat Sade. (Soekanto, 2002)

Sebagai salah satu daya tarik yang mengandalkan budaya masyarakat sebagai basis atraksi, pengembangan pariwisata di Dusun Sade tentunya memberikan dampak bukan hanya pada tatanan sosial namun juga perubahan budaya. Hal ini merupakan konsekuensi logis pengembangan pariwisata di Dusun Sade yang dikembangkan melalui konsep desa wisata. Untuk itulah Peneliti tertarik untuk melihat seberapa besar dampak sosial budaya dari pengembangan Dusun Sade sebagai dusun wisata di Kabupaten Lombok Tengah.

Berdasarkan latar belakang diatas maka rumusan masalah yang tepat untuk penelitian ini adalah :

1. Bagaimana kondisi sosial budaya di Dusun Sade sebelum ditetapkan sebagai dusun wisata?

2. Bagaimana kondisi sosial budaya di Dusun Sade pasca ditetapkan sebagai dusun wisata?

\section{KEPUSTAKAAN}

Dalam penelitian dampak sosial budaya pengembangan Dusun Sade sebagai dusun wisata di kabupaten Lombok tengah digunakan beberapa konsep yang digunakan untuk mengakaji diantaranya :

1. Konsep Dampak Sosial Budaya

Menurut Martin (1998:171) dalam Pitana dan Gayatri 2005, dampak sosial budaya selam ini cenderung mengasumsikan bahwa akan terjadi perubahan sosial budaya akibat kedatangan wisatawan dengan tiga asumsi umum yaitu :

a. Perubahan dibawa sebagai akibat adanya instrusi dari luar, umumnya dari sistem sosial budaya yang superordinat terhadap budaya penerima yang lebih lemah

b. Perubahan tersebut umumnya destruktif bagi budaya indigenous c. Perubahan tersebut akan membawa pada homogenisasi budaya, dimana identitas etnik lokal akan tenggelam dalam bayangan sistem industri dengan teknologi barat, birokrasi nasional dan multinasional, $a$ consumer-oriented economy, dan jet-age lifestyle

Namun pada penelitian ini peneliti menggunakan konsep dampak sosial budaya yang dikemukakan oleh Pizam dan Milman (1984) yang hanya terfokus pada dampak sosial budaya pada mata pencaharian (perubahan pekerjaan, distribusi pekerjaan), sistem organisasi dan aspek budaya (bahasa) yang sesuai dengan indikator kebudayaan universal.

\section{Konsep Kebudayaan}

"Kebudayaan adalah seluruh cara kehidupan dari masyarakat dan tidak hanya mengenai sebagian tata cara hidup saja yang dianggap lebih tinggi dan lebih diinginkan". (Ralph dan Linton dalam Siregar , 2002)

"Kebudayaan adalah seluruh sistem gagasan dan rasa, tindakan, serta karya yang dihasilkan manusia dalam kehidupan bermasyarakat, yang dijadikan miliknya dengan belajar". ( Koentjaraningrat, 2014:72)

Terdapat 7 (tujuh) unsur kebudayaan universal yaitu bahasa, sistem pengetahuan, organisasi sosial, sistem peralatan hidup dan teknologi, sistem mata pencarian hidup, sistem religi dan kesenian.

Ketujuh unsur-unsur kebudayaan universal memiliki tiga wujud kebudayaan yang didalamnya terkandung sistem gagasan (ide), tindakan dan hasil karya (kebendaan).

\section{Konsep Desa Wisata}

"Yang dimaksud desa wisata adalah pengembangan desa menjadi destinasi wisata dengan sistem pengelolaan yang bersifat dari, oleh, dan untuk masyarakat" (Putra dan Pitana, 2010:70). Konsep desa wisata yang dimaksud disini adalah pembangunan dan pengelolaan desa wisata yang berada di tangan masyarakat desa. Masyarakat berperan aktif mengembangkan desa wisata baik melalui lembaga koperasi atau yayasan, proaktif mengelola daya tarik wisata di daerahnya dengan mengundang wisatawan untuk datang sekaligus untuk bermalam karena desa wisata juga menawarkan pelayanan akomodasi. 


\section{METODE PENELITIAN}

Penelitian ini dilakukan di Dusun Wisata Sade yang berada di Desa Rembitan Kecamatan Pujut, Kabupaten Lombok Tengah. Metode yang digunakan dalam penelitian ini yaitu deskriptif kulaitatif yang akan terfokus pada perubahan yang terjadi sebelum dan sesudah Dusun Sade menjadi dusun wisata. Dalam penelitian ini digunakan data primer yang didapatkan langsung oleh Peneliti berupa kondisi sosial budaya sebelum dan sesudah dusun sade menjadi dusun wisata yang meliputi aspek mata pencaharian masyarakat, sistem organisasi dan bahasa. Data yang ada dalam penelitian ini didapat melalui observasi, wawancara dengan kepala dusun (jero keliang) dan masyarakat lokal yang bekerja di sektor pariwisata (local guide, pengrajin, dan pemilik galeri). Teknik analisis data yang digunakan dalam penelitian ini yaitu teknik analisis data model alir dimana data yang telah terkumpul kemudian diverifikasi dari awal kemudian data mengenai perubahan-perubahan sosial budaya yang terjadi di dusun sade di sajikan dalam bentuk pemaparan analisis untuk kemudian ditarik kesimpulan tentang dampak sosial yang terjadi di Dusun Sade.

\section{HASIL DAN PEMBAHASAN}

Dusun Wisata Sade merupakan salah satu dusun yang terletak di Desa Rembitan Kecamatan Pujut, Kabupaten Lombok Tengah, awalnya dusu nini mulai didiami pada tahun 1070 M. Kata Sade sendiri berarti obat, hal ini dikarenakan pada zaman dahulu orang-orang yang ingin melakukan kegiatan spriritualitas seperti menjernihkan hati dan jiwa akan datang ke bukit yang merujuk pada Dusun Sade.

Masyarakat di Dusun Sade memiliki keterikatan keluarga yang erat, hal ini dikarenakan pernikahan mereka menggunakan sistem endogami. Selain itu terdapat hal unik lainnya di Dusun Sade yaitu adanya kepercayaan Islam Waktu Telu (Islam Tiga Waktu), namu sekarang ini pemeluknya hanya tingga satu persen (1\%).

Sebagai dusun yang masih mempertahankan adat Suku Sasak, masyarakat Dusun Sade memiliki kekhasan arsitektur bangunan rumah tradisional yang hingga saat ini bertahan. Rumah tradisonal ini merupakan rumah asli dari Suku Sasak yang mendiami Dusun Sade sampai 15 generasi. Keunikan yang dimiliki rumah ini meliputi atapnya yang masih terbuat dari alang-alang, lantai rumah yang masih terbuat dari tanah serta pembagian ruang yang ada.

Pembagian ruang rumah adat Sade terdiri dari inen bale dan bale dalem. Inen bale merupakan ruang induk yang meliputi bale luar (kamar tidur) dan bale dalem yang difungsikan sebagai tempat untuk menyimpan harta benda. Sedangkan untuk bagian bale dalem terdapat dapur dan alat-alat rumah tangga lainnya.

Setelah berkembang menjadi dusun wisata tidak membuat Dusun Sade kehilangan keaslian dan kekhasan arsitektur rumah adat Suku Sasak. Namun inilah yang membuat daya tarik yang berbeda dari tempat wisata lainnya di Lombok. Dibalik perkembangan bariwisata di Dusun Wisata Sade, terdapat perubahan pada tatanan kebudayaan dan kehidupan sosial mereka. Perubahan- perubahan tersebut akan diuraikan dalam pembahasan berikut ini.

\subsection{Kondisi Sosial Budaya di Dusun Sade Sebelum Menjadi Dusun Wisata}

\section{a. Mata Pencaharian}

Sebelum menjadi dusun wisata, masyarakat di Dusun Sade mayoritasnya bekerja di sekor pertanian. Maysarakat lokal di Dusun Sade menggantungkan hidupnya dari hasil pertanian untuk memenuhi kebutuhan sehari-hari. Biasanya mereka mengolah sawah yang ditanam menggunakan sistem tadah hujan. Hal ini disebabkan karena sawah di Dusun Sade belum menggunakan sistem irigasi, sehingga masyarakat hanya bisa memanen sekali dalam setahun.

Ketika mengolah lahan pertanian seperi sawah, masyarakat Sade dulunya menggunakan bantuan sapi ata kerbau. Mereka percaya bahwa kedua hewan tersebut dapat memberi kesuburan bagi lahan pertanian mereka. Masyarakat Sade memang masih memegang nilai-nilai luhur yang ada bahkan dalam pekerjaan keseharian mereka.

\section{b. Sistem organisasi}

Sebelum menjadi dusun wisata, ketika menyangkut sistem organisasi di Sade maka akan mengarah pada sistem pemerintahan tingkat komunitas yang dipimpin oleh jero keliang. Jero keliang ini merupkan sebutan untuk kepala dusun yang dipilih berdasarkan garis ketrunan. Namun, meski dipilih secara turun-temurun pemilihan jero kleiang di dusun 
sade tetap mengedepankan musyawarah. Adapun tugas dan fungsi dari jero keliang yaitu :

1. Pelaksaan birokrasi di Dusun Sade di bawah pemerintahan kepala desa

2. Pengemban adat sekaligus ketua adat, biasanya dibantu oleh

Selain pemerintahan yang masih sederhana dan bersifat lokal, organisasi komunal yang ada di tingkat komunitas Dusun Sade yaitu bebanjar. Bebanjar merupakan jenis perkumpulan atau asosiasi tardisional yang merupakan wujud dari rasa tolong menolong. Biasanya masyarakat akan berkumpul pada saat tetangga memiliki acara pesta (begawe), hajatan (epen gawe) maupun upacara kematian.

\section{c. Bahasa}

Salah satu media komunikasi verbal yang ada yaitu bahasa. Setiap daerah pasti mengenal bahasa yang berbeda-beda, hal ini menunjukkan bahwa setiap daerah juga memiliki budaya yang berbeda pula. Salah satu komunitas suku sasak yang masih eksistensinya masih dikenal sekarang salah staunya berada di Dusun Sade. masyarakat Sade merupakan Suku Sasak yaitu suku asli pulau Lombok. Dalam keseharianya masyarakat Sade menggunakan bahasa sasak untuk berkomunikasi. komunitas Sasak Sade mengenal dua dialek bahasa yaitu :

1. Base jamak (bahasa sasak kasar)

Base jamak merupakan salah satu dialek bahasa sasak yang tergolong kedalam bahasa sasak kasar. Biasanya base jamak ini akan digunakan oleh masyarakat Sade untuk berkomunikasi dengan sesama warga di dusun tersebut.

2. Base dalem (bahasa sasak halus)

Base dalem merupakan dialek bahasa sasak yang terbilang halus atau lebih sopan. Biasanya jenis bahasa sasak ini akan digunakan untuk bekomunikasi dengan tokoh-tokoh adat atau dalam bahasa sasaknya dikenal dengan sebutan dengan toaq. Selain itu bahas sasak halus juga digunakan untuk berkomunikasi saat ada upacara perkawinan yang disebut sorong serah aji krame.

\subsection{Kondisi Sosial Budaya di Dusun Sade Pasca Ditetapkan Sebagai Dusun Wisata \\ a. Mata Pencaharian}

Harus diakui bahwa pariwisata merupakan salah satu sektor yang memberikan peluang pekerjaan jika dibandingkan dengan sektor lainnya. Hal tersebut kemudian mampu menarik minat orang untuk merapat ke sektor pariiwsata. Oleh karena itu terjadi transformasi pekerjaan dari sektor pertanian ke sektor pariwisata. (Pitana dan Diarta, 2009)

Hadirnya pariwisata membuka lapangan kerja yang bervariasi, mulai dari jasa layanan pariwisata dan usaha akomodasi pariwisata. Begitu juga perkembangan pariwisata di Dusun Sade yang membawa perubahan seperti terjadinya transformasi pekerjaan dari awalnya masyarakat bergelut dibidang pertanian sampai berubah mempunyai pekerjaan di bidang pariwisata. Adapun transformasi pekerjaan yang ada di Dusun Sade meliputi :

1. Pemandu lokal (local guide)

Adanya transformasi pekerjaan dari petani kemudian bekerja sampingan sebagai pemandu lokal merupakan salah satu akibat dari hadirnya pariwisata di Dusun Sade. Awalnya masyarakat hanya menggantungkan hidupnya dari hasil pertanian, namun sekarang mereka bisa memperoleh keuntungan dari pekerjaan sampingan sebagai pemandu lokal.

Pemandu lokal di Dusun Sade bertugas untuk mengantar wisatawan berkeliling melihat kehidupan asli Suku Sasak. Wisatawan akan dikenalkan pada sejarah, tradisi serta keunikan yang ada di Dusun Sade ketika mereka melakukan tracking. Melalui cara ini wisatawan lebih mudah belajar mengenai keraifan lokal yang ada.

Pemandu lokal di Dusun Sade bekerja dan dibayar dengan sistem willingness to pay. Artinya mereka tidak mamatok tarif yang pasti kepada wisatawan. Namun mereka tetap diberi tip oleh wisatawan yang mereka pandu. Selain itu mereka juga digaji dari dana bantuan pemerintah yang diberikan untuk dusun wisata Sade.

Keuntungan finansial yang diperoleh dari status Dusun Sade sebagai dusun wisata tentu membuat masyarakat lokal yang memiliki kemampuan sebagai pemandu lokal memilih pekerjaan ini sebagai pekerjaan sampingan. Sekarang masyarakat lokal yang bekerja sebagai pemadu lokal di Dusun Sade berjumlah kurang lebih 40 orang yang semuanya adalah laki-laki. hal ini merupakan salah satu cara masyarakat memanfaatkan perkembangan 
pariwisata dengan status Dusun Sade sebagai dusun wisata.

\section{Pengrajin dan Penjual Tenun}

Wanita yang ada di Dusun Sade memang memilki kemampuan untuk menenun. Mereka diwajibkan bisa menenun ketika menginjak usia remaja. Oleh karena itu banyak sekali ragam tenun yang dihasilkan oleh wanita di Sade. Hadirnya wisatawan yang berkunjung ke Dusun Sade memberikan peluang mereka untuk menjual hasil tenun sebagai oleh-oleh khas Sade.

Ragam hias tenun yang ada di Dusun Sade juga beragam. Ragam hias yang biasa dibuat yaitu ragam hias selolot, kelungkung, tapok kemalo, batang empat, ragi genep, berang, bebasak, tuntang balik, sabuk antang dan umbak. Selain menjual tenun, masyarakat lokal juga menjual hasil kerajinan seperti tas, gelang, klaung dan gantungan kunci khas sade. mereka menyediakan berbagai souvenir untuk wisatawan sehingga mereka mendapatkan keuntungan dari hasil penjualan tersebut.

3. Penjual lukisan

Selain pemandu lokal dan pengrajin, masyarakat lokal yang mempunyai kemampuan melukis membuka galeri sederhana dirumahnya. Mereka membuat lukisan untuk dipajang dan dinikmati oleh wistawan. Lukisan tersebut juga bisa dibeli jika ada wisatawan yang berminat. Ini merupakan salah satu cara masyarakat lokal di Sade memanfaatkan status Dusun Wisata Sade. Selain itu pekerjaan sebagai seniman yang membuat lukisan merupakan ekspresi kreatif mereka melalui pemanfaatan keahlian untuk kepentingan wisatawan.

\section{b. Sistem Organisasi}

Setelah hadirnya pariwisata di Dusun Sade terjadi kompleksitas dalam kelembagaan di tingkat komunitas. Dengan adanya perkembangan pariwisata membuat distribusi pekerjaan di Sade memiliki spesialisasi masingmasing. Hal ini dikarenakan perlunya struktur organisasi yang lebih khusus untuk mengatur kegiatan wisata yang ada di Sade. Berikut ini merupakan beberapa organisasi yang ada di Dusun Wisata Sade :

\section{Pengelola Dusun Wisata Sade}

Pengelola Dusun Wisata Sade ini memiliki tugas untuk mengatur birokrasi serta manajemen di Dusun Sade, meliputi manajemen internal maupun eksternal yang berhubungan dengan pemerintah.

\section{Kelompok Sadar Wisata (Pokdarwis)}

Kelompok sadar wisata (Pokdarwis) yang ada di Dusun Sade bernama Terune Wisata. Terune dalam bahasa Sasak berarti lakilaki. Pokdarwis yang ada di Dusun Sade seluruh anggotanya adalah laki-laki. Tugas dan fungsi pokok dari pokdarwis ini yaitu mewujudkan visi dan misi Dusun Wisata Sade sebagai dusun percontohan yang memegang teguh filosofi budaya lokal.

\section{c. Bahasa}

Sejak adanya pariwisata banyak interaksi antara masyarakat lokal di Sade dengan wisatawan yang datang. Interaksi khususnya terjadi lebih intensif antara wisatawan dengan masyarakat lokal yang bekerja sebagai pemandu lokal maupun penjual oleh-oleh.

Pasca menjadi dusun wisata penggunaan bahasa asing menjadi hal biasa didengar ditengah-tengah masyarakat di Dusun Sade. Banyaknya wisatawan asing yang berkunjung membuat masyarakat harus bisa menguasai bahasa asing untuk berkomunikasi dengan wisatawan. Wisatawan asing yang mendominasi Dusun Wisata Sade berasal dari Eropa dan Asia, Penggunaan bahasa asing yang menonjol bisa terlihat dari pemandu lokal. Mereka tidak hanya fasih menggunakan bahasa Sasak maupun Indonesia, namun mereka juga bisa menguasai bahasa asing seperti bahasa Inggris, Perancis dan Jepang. Perubahan penggunaan bahasa di Sade merupakan salah satu dampak yang ditimbulkan pasca Dusun Sade menjadi dusun wisata.

Dari uraian tersebut diatas, menunjukkan pariwisata memberikan dampak pada tatanan kehidupan sosial dan budaya masyarakat di Dusun Sade. berikut ini merupakan tabel yang menunjukkan kondisi sosial budaya di Dusun Sade.

Tabel 4.1. Dampak Sosial Budaya di Dusun Wisata Sade

\begin{tabular}{|c|c|c|}
\hline Aspek & Sebelum & Sesudah \\
\hline $\begin{array}{c}\text { Mata } \\
\text { pencaharian }\end{array}$ & $\begin{array}{c}\text { Pekerjaan utama } \\
\text { adalah petani }\end{array}$ & $\begin{array}{l}\text { a. Pekerjaan utama } \\
\text { yaitu Petani } \\
\text { b. Pekerjaan } \\
\text { sampingan yaitu } \\
\text { pemandu lokal, } \\
\text { pengrajin dan } \\
\text { pembuat tenun, } \\
\text { penjual lukisan }\end{array}$ \\
\hline $\begin{array}{c}\text { Sistem } \\
\text { Organisasi }\end{array}$ & $\begin{array}{l}\text { a. Sistem } \\
\text { pemerintahan }\end{array}$ & $\begin{array}{l}\text { Munculnya } \\
\text { spesialisasi }\end{array}$ \\
\hline
\end{tabular}




\begin{tabular}{|c|l|l|}
\hline \multirow{7}{*}{ Bahasa } & $\begin{array}{l}\text { tingkat dusun } \\
\text { yang dipimpin } \\
\text { jero keliang } \\
\text { b. Perkumpulan } \\
\text { tingkat } \\
\text { komunitas yang } \\
\text { disebut } \\
\text { bebanjar }\end{array}$ & $\begin{array}{l}\text { organisasi seperti } \\
\text { pengelola dusun } \\
\text { wisata dan kelompok } \\
\text { sadar wisata } \\
\text { (pokdarwis) }\end{array}$ \\
\hline \multirow{3}{*}{$\begin{array}{l}\text { Penggunaan basa } \\
\text { jamak (bahasa } \\
\text { Sasak kasar) dan } \\
\text { basa dalem } \\
\text { (bahasa sasak } \\
\text { halus) }\end{array}$} & $\begin{array}{l}\text { Masyarakat mulai } \\
\text { mengenal bahasa } \\
\text { asing seperti bahasa } \\
\text { Inggris, Jepang dan } \\
\text { Perancis }\end{array}$ \\
\hline
\end{tabular}

Sumber : Hasil Penelitian 2017

\section{PENUTUP}

\subsection{Simpulan}

Dampak sosial budaya yang terjadi pada masyarakat dusun sade mengarah pada dampak positif. Jika sebelum adanya pariwisata masyarakat hanya bekerja di sektor pertanian, maka setelah adanya pariwisata masyarakat memiliki peluang bekerja di sektor pariwisata. Begitu pula dengan sistem organisasi yang ada, sebelum pariwisata berkembang masyarakat Sade hanya mengenal organisasi sosial tingkat komunitas seperti bebanjar. Namun, setelah pariwisata berkembang masyarakat Sade memiliki organisasi sosial yang memiliki spesialisasi fungsi untuk kegiatan pariwisata seperti pengelola dusun wisata dan kelompok sadar wisata (pokdarwis).

Salah satu unsur yang mengalami perubahan yaitu bahasa. Sebelumnya masyarakat lokal hanya mengenal bahasa Sasak untuk berkomunikasi. Namun, setalah pariwisata berkembang dengan banyaknya wisatawan yang datang membuat masyarakat yang bekerja di sektor pariwisata harus bisa menguasai melainkan bahasa asing selain bahasa Sasak.

Perubahan sosial budaya yang terjadi di Dusun Sade menunjukkan bahwa kebudayaan masyarakat tidak lemah. Walaupun terjadi perubahan namun kebudayaan mereka tidak destruktif dan identitas etnik lokal tidak tenggelam dalam bayangan kegiatan pariwisata.

\subsection{Saran}

Masyarakat lokal di Dusun Sade harus menjaga kekhasan budaya lokal yang merupakan modal pengembangan pariwisata. Sebagai pemilik kebudayaan itu sendiri, masyarakat harus melihat dinamika perubahan yang positif. Pariwisata tentunya membawa berbagai dampak dalam kehidupan sosial budaya masyarakat Sade, oleh karena itu sudah menjadi tanggung jawab untuk menjaga tradisi serta keaslian adat dan istiadat di tengah fenomena pariwisata yang terjadi.

Untuk pemerintah dan pengelola Dusun Wisata Sade agar tetap menjaga kemitraan yang sudah dibangun untuk mengembangkan Dusun Wisata Sade menjadi daya tarik wisata yang selalu eksis dengan keunikan serta kekhasan yang ada.

Untuk Peneliti selanjutnya diharapkan mampu melihat bagaimana pengelolaan Dusun Wisata Sade agar sebagai acuan pengelolaan yang ideal di sebuah dusun wisata.

\section{DAFTAR PUSTAKA}

Koentjaraningrat. 2014. Pengantar Antropologi I.Jakarta: PT.Rineka Cipta

Pitana, I. G. , Gayatri. P. G. 2005. Sosiologi Pariwisata. Yogyakarta: Penerbit Andi

Pitana, I. G. , Diarta, I. K. S. 2009. Pengantar Ilmu Pariwisata. Jakarta: Penertbit Andi

Putra, I. N. D. , Pitana, I. G. 2010. Pariwisata Pro-Rakyat. Jakarta : Kementrian Kebudayaan dan Pariwisata Republik Indonesia

Siregar, L. (2002). Antropologi dan Konsep Kebudayaan. Jurnal Antropologi Papua, 1(1), 112.

Soekanto, S. 2002. Sosiologi Suatu Pengantar. Jakarta: PT.Raja Grafindo Persada 